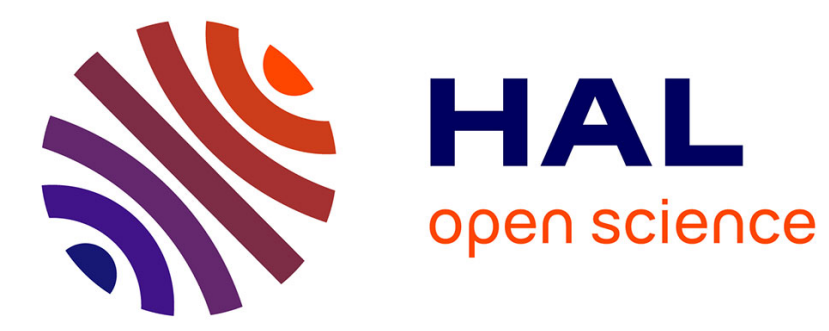

\title{
A new detailed plasma-chemistry model for the potential impact of blue jet streamers on atmospheric chemistry
}

Chen Xu, Nathalie Huret, Matthieu Garnung, Sébastien Celestin

\section{To cite this version:}

Chen Xu, Nathalie Huret, Matthieu Garnung, Sébastien Celestin. A new detailed plasma-chemistry model for the potential impact of blue jet streamers on atmospheric chemistry. Journal of Geophysical Research: Atmospheres, 2020, 6, 10.1029/2019JD031789 . insu-02504762

\section{HAL Id: insu-02504762}

\section{https://hal-insu.archives-ouvertes.fr/insu-02504762}

Submitted on 30 Mar 2020

HAL is a multi-disciplinary open access archive for the deposit and dissemination of scientific research documents, whether they are published or not. The documents may come from teaching and research institutions in France or abroad, or from public or private research centers.
L'archive ouverte pluridisciplinaire HAL, est destinée au dépôt et à la diffusion de documents scientifiques de niveau recherche, publiés ou non, émanant des établissements d'enseignement et de recherche français ou étrangers, des laboratoires publics ou privés. 


\section{JGR Atmospheres}

\author{
RESEARCH ARTICLE \\ 10.1029/2019JD031789 \\ Key Points: \\ - A detailed ion-neutral chemistry \\ model has been developed to \\ simulate the chemical impact of blue \\ jet streamers \\ - A time-dependent reduced electric \\ field is used for blue jet streamer \\ discharge, and the shape in time \\ makes critical chemical impact \\ - Ozone is produced by BJ streamer in \\ the first $100 \mathrm{~s}$, consumed in hours \\ and decreases to lower density than \\ in a no-discharge case
}

Supporting Information:

- Supporting Information S1

Correspondence to:

N. Huret,

n.huret@opgc.fr

Citation:

Xu, C., Huret, N., Garnung, M., \& Celestin, S. (2020). A new detailed plasma-chemistry model for the potential impact of blue jet streamers on atmospheric chemistry. Journal of Geophysical Research: Atmospheres,

125, e2019JD031789. https://doi.org/ 10.1029/2019JD031789

Received 10 OCT 2019 Accepted 12 FEB 2020 Accepted article online 20 FEB 2020

(C)2020. American Geophysical Union. All Rights Reserved.

\section{A New Detailed Plasma-Chemistry Model for the Potential Impact of Blue Jet Streamers on Atmospheric Chemistry}

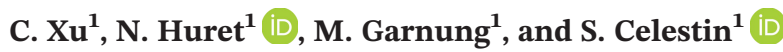 \\ ${ }^{1}$ LPC2E/CNRS - Université d'Orléans, Orléans, France
}

\begin{abstract}
A detailed ion-neutral chemistry model named MiPO-Streamer model has been developed to simulate the impact of blue jet streamers on stratospheric chemistry. It is based on the MiPLaSMO model (Microphysical and Photochemical Lagrangian Stratospheric Model of Ozone) widely used over the last 20 years to interpret balloon and satellite measurements associated with stratospheric ozone. In this study, instead of using a reduced electric field with constant value during blue jet streamer discharge process, we used a time-dependent reduced electric field coming from an explicit streamer model. The simulations are performed on daytime/nighttime and in 2-day long-term duration at $27 \mathrm{~km}$ where the catalytic cycle of $\mathrm{NO}_{x}$ is the most efficient to destroy ozone. Among 117 species considered, we put the focus on nitrogen, oxygen, chlorine, and bromine species, and ozone perturbation. The model results indicate that the densities of neutral species through an electrodynamic streamer simulation show an impact of a factor 2 as compared to the pulse-based simulation at $27 \mathrm{~km}$.
\end{abstract}

\section{Introduction}

The transient luminous events (TLEs) family includes blue jets (BJs), sprites, and elves, which occur in the stratosphere and mesosphere (roughly from 20 to $100 \mathrm{~km}$ ). This study focuses on the chemical impact of the streamers associated with blue jets and gigantic jet events, which are developed above thunderstorms. Such electric discharges are believed to be due to electric charge imbalance inside the thunderstorms (Krehbiel et al., 2008). The characteristics of the discharge are typically upward by the vertical velocity of $\sim 100 \mathrm{~km} / \mathrm{s}$ with a duration of a $200-300 \mathrm{~ms}$ (Wescott et al., 1996).

Upward streamers of BJs produce a narrow cone confined by an aperture angle (Raizer et al., 2006, 2007). Thus, BJ is similar to streamer corona where the discharge is a self-similar plasma fractal structure (Pasko et al., 2002; Petrov \& Petrova, 1999; Wiesmann \& Pietronero, 1986). The BJ fractal structure can be positive (Pasko et al., 1996) or negative (Sukhorukov \& Stubbe, 1997) streamers. The fractal dimension stays almost constant when the streamers propagate at different altitudes because of the constant reduced electric field in streamer head (Popov, 2002). The strong electric field near the streamer tip impacts the streamer propagation and the shape of electric field dominates the propagation direction. The spatial distribution of electric field determines the propagation probability (Popov et al., 2016).

The altitude range where blue jets happen is located in the stratospheric ozone layer. It is well known that electric discharges in the middle atmosphere produce $\mathrm{NO}_{x}\left(\mathrm{NO}_{x}=\mathrm{NO}+\mathrm{NO}_{2}\right)$ as a result of the intense heating and/or shock wave from a lightning channel (Chameides et al., 1987), by the recombination reactions and ion-neutral reactions (Griffing, 1977; Kossyi et al., 1992) of atomic oxygen and nitrogen. In addition, prior studies showed that TLEs should impact $\mathrm{NO}_{x}$ concentration significantly in the middle atmosphere (Gordillo-Vázquez, 2008; Neubert et al., 2008; Peterson et al., 2009). In the stratosphere, the $\mathrm{NO}_{x}$ species interacts strongly with ozone chemistry through catalytic cycles (Cohen \& Murphy, 2003; Johnston, 1971).

With a simplified plasma chemistry model, Mishin (1997) reported the impact of such discharge on ozone content. They highlight an enhancement of $10 \%$ of nitric oxide and $0.5 \%$ of ozone at $30 \mathrm{~km}$ by blue jet streamers. Smirnova et al. (2003) updated chemical composition and ionization, attachment rates to study the impact of electric field perturbations on the lower stratosphere. Their simulation results indicate the importance of reactions and their rate coefficients in BJ streamer electron density $\left(n_{e^{-}}\right)$governed processes (electric field-driven processes). More recently, Winkler and Notholt (2015) (referred to as W2015 here after) have developed a detailed plasma chemistry model (including 88 species and more than 1,000 reactions) to investigate $\mathrm{BJ}$ streamers and leaders impact. The relative streamers caused an increase of $\mathrm{NO}_{x}$, and $\mathrm{O}_{3}$ 
reported by W2015 are much larger than the previous two studies (Mishin, 1997; Smirnova et al., 2003). For instance, at $30 \mathrm{~km}$, the $\mathrm{NO}_{x}$ increase of W2015 is two orders of magnitude larger than that of Mishin (1997) and Smirnova et al. (2003). W2015 indicated a relative increase of $2 \%$ of $\mathrm{O}_{3}$ at $30 \mathrm{~km}$, while an increase of $0.03 \%$ in $\mathrm{O}_{3}$ was found by Smirnova et al. (2003) and an increase of $0.5 \% \mathrm{O}_{3}$ by Mishin (1997). Concerning the impact of the leader part in $\mathrm{NO}_{x}$ and $\mathrm{O}_{3}$ by W2015, which is not significant at $27 \mathrm{~km}$, it will not be considered as a first approach in this study. The previous studies focus on the first hundred seconds after the discharge event, whereas $\mathrm{NO}_{x}$ species production in the stratosphere interact with the ozone chemistry on a timescale of several days.

The objective of our study is the accurate evaluation of potential impact of blue jet streamers on atmospheric chemistry. It includes two investigations under different duration times after the event: first, at the small time scale of a few seconds (100 s), for investigating the excited species and ions perturbation; second, at the large time scale of a few days, for investigating the $\mathrm{NO}_{x}$, bromine and chlorine family perturbation, and the induced $\mathrm{O}_{3}$ modification.

In this study, we first present the developed plasma-chemistry model, the streamer parameterizations, and the characteristics of the simulations. Then the results of model validation on neutral chemistry and plasma chemistry are compared to W2015. The last part presents the obtained results of the chemistry impact by electric field parameterization between a simplified pulse streamer and a realistic streamer. Moreover, the results of long-time (2-day) chemistry impact by realistic streamer are presented.

\section{Model Description}

\subsection{MiPO-Streamer Model Description}

The MiPO-Streamer model developed in this study is based on the Microphysical and Photochemical Lagrangian Stratospheric Model of Ozone (MiPLaSMO), which was widely used over the last 20 years to interpret balloon and satellite measurements associated with stratospheric ozone (e.g., Brogniez et al., 2003; Croizé et al., 2015; Grossel et al., 2010; Huret et al., 2003; Rivière et al., 2000; Riviere et al., 2002). This model describes the time evolution of the chemical, microphysical, and thermodynamical properties of an air parcel through both a detailed chemistry scheme (133 photochemical gaseous and heterogeneous reactions) and microphysics calculations (size distribution and nature of aerosols) for five types of stratospheric particles. This model is described in more detail by Rivière et al. (2000). In this study, it is used in its box model version and considers oxygen, hydrogen, nitrogen, chlorine, and bromine gaseous chemical families. The nonlinear system of equations governing the chemical species evolution is converted into a linear system of equations using a semi-implicit symmetric (SIS) method. It allows to conserve the number of atoms and molecules. A description of this method can be found in the work by Ramaroson et al. (1992). The time step of the model can be easily adapted with typically 5 min during day and night, reduced to $30 \mathrm{~s}$ for twilight periods, and to $10^{-11} \mathrm{~s}$ during the electrical discharge.

Compared to MiPLaSMO model, the chemical scheme considered in MiPO-Streamer model has been enlarged following W2015, including plasma-chemistry reactions. Now MiPO-Streamer model considers 117 species and 1,760 reactions. The set of species are listed in Table S1 of the supporting information.

Compared to the model used in W2015, the MiPO-Streamer model considers more neutral chemistry relevant for stratospheric investigations. Such as more bromine family $\left(\mathrm{Br}_{y}\right)$, chlorine family $\left(\mathrm{Cl}_{y}\right)$, and hydrogen species and their corresponding reactions, and more photochemistry reactions of $\mathrm{NO}_{x}$ (for details, see Table S2). $\mathrm{Cl}_{y}$ and $\mathrm{Br}_{y}$ chemistry make significant effect on $\mathrm{O}_{3}$ destruction, especially in the stratosphere (Prather \& Watson, 1990; Yung et al., 1980). $\mathrm{O}_{3}$ has a long photochemical lifetime in lower stratosphere; thus, photochemistry is vital for $\mathrm{O}_{3}$ production in the stratosphere, particularly in the tropics (Avallone \& Prather, 1996). The stratospheric $\mathrm{O}_{3}$ chemistry is particularly perturbed through catalytic cycles associated with $\mathrm{Cl}_{y}, \mathrm{Br}_{y}$, and hydrogen-related reactive nitrogen compounds (Murphy et al., 1993). For instance, $\mathrm{Cl}_{y}$ chemistry is coupled to $\mathrm{NO}_{3}$ via $\mathrm{ClONO}_{2}$ and the hydrogen cycle is coupled to $\mathrm{NO}_{x}$ via $\mathrm{HO}_{2} \mathrm{NO}_{2}$. Therefore, the simulation of chemistry impact by BJ streamer used MiPO-Streamer model is more comprehensive and reliable on stratospheric chemistry mechanism than that in W2015. The rate coefficients of neutral chemistry and photolysis rates are taken from those provided by the Jet Propulsion Laboratory (referred to as JPL here after) (Sander et al., 2006). 
The set of reactions associated with plasma chemistry processes in the model is that of W2015, including electric field-driven processes, electron attachment, electron detachment, associative and penning ionization, positive ion chemistry, negative ion chemistry, electron-ion recombination, and ion-ion recombination. The electric field-driven processes enhance the densities of electrons, atomic nitrogen, atomic oxygen, and the densities of excited states of atomic nitrogen and oxygen, molecules of nitrogen and oxygen. The reaction rate coefficients of electric field-driven processes are calculated using the Boltzmann solver BOLSIG+ (Hagelaar \& Pitchford, 2005). The rate coefficients of other plasma chemistry reactions are taken from W2015.

\subsection{Streamer Parameterizations}

In the streamer discharge, the production and loss of electrons are driven by ionization and attachment processes, which depend on the local electric field. In the present work, we use two model cases of streamer electric fields: one is a simple constant pulse of electric field widely used in blue jet research (e.g., GordilloVázquez, 2008; Sentman et al., 2008; Winkler \& Notholt, 2014; Winkler \& Notholt, 2015); the other one is a realistic streamer electric field during the discharge process obtained from a self-consistent electrodynamic streamer model (Ihaddadene \& Celestin, 2017).

\subsubsection{Pulse Streamer Model}

As used in W2015, at a given location passed by streamer tip, the electric field is approximated with a simple boxcar field (rectangular function) (Mishin \& Milikh, 2008; Raizer et al., 2007). Thus, the streamer field is constant during the discharge process with a reduced electric field value of $\theta=\frac{\mathrm{E}}{\mathrm{N}}=6 \times 10^{-15} \mathrm{~V} \mathrm{~cm}^{2}$ $(600 \mathrm{Td})$ for all the altitudes. In the following, we refer to this model as the pulse streamer case.

\subsubsection{Electrodynamic Streamer Model}

In the present work, we also make use of a plasma fluid model to capture a realistic time dynamics of the electric field at a given location during the passage of a streamer. This electrodynamic model is based on the numerical modeling of drift-diffusion equations for charged species coupled with Poisson's equation (e.g., see Ihaddadene \& Celestin, 2015, 2017). In the case of streamer discharges in air, it is important to note that the electron density formed in the streamer channel reaches a maximum analogous to a saturation process (e.g., Dyakonov \& Kachorovsky, 1989) on the order of $10^{14} \mathrm{~cm}^{-3}\left(\frac{\mathrm{N}}{\mathrm{N}_{0}}\right)^{2}$, where $\mathrm{N}$ is the local air density and $\mathrm{N}_{0}$ is the air density at the Earth's surface (e.g., Babaeva \& Naidis, 1996; Pasko et al., 1998).

As the electron density is exponentially dependent on the duration of the applied electric field at a given location, and the MiPO-Streamer model does not solve for the electric field self-consistently, small variations in the rate coefficients would lead to dramatic discrepancies in the electron density in the streamer channel. To circumvent this issue, we have found an analytical fit of the rising electric field in the streamer head. This analytical fit is used in the MiPO-Streamer model in a second step. The field rises until the typical electron density of the streamer channel is reached. The resulting difference in the duration of the rising field between the electrodynamic simulation and the analytical fit is negligible (as obvious in Figure $5 \mathrm{~b}$ of this study, where one can appreciate the very sharp slope in the electron density). After reaching its maximum, the field is considered to relax linearly in time down to $0 \mathrm{Td}$ over the same timescale as that found in the electrodynamic streamer simulation.

\subsection{Initialization}

We take the event reported by Chou et al. (2011) as an example. That event is the first type II gigantic jet observed from the ground. It occurred over a thunderstorm in Fujian province of China on 22 July 2007 and was observed from Lulin Observatory $\left(121^{\circ} \mathrm{E}, 23^{\circ} \mathrm{N}\right)$ in Taiwan by three sight-aligned WATEC 100-N cameras. During the event process, a blue starter appeared above a $100 \mathrm{~km}$ diameter thunderstorm. About $100 \mathrm{~ms}$ later, a blue jet occurred near the same cloud top region. And then it developed into a gigantic jet reaching at least $\sim 65 \mathrm{~km}$ in $50 \mathrm{~ms}$ (Chou et al., 2011). All the MiPO-Streamer model validations and BJ streamer simulations are shown at $27 \mathrm{~km}$, in the middle stratosphere where the catalytic cycle of $\mathrm{NO}_{x}$ is efficient to destroy ozone (Portmann et al., 2012).

The initial values of temperature, pressure, and all gaseous species volume mixing ratio (VMR) come from a three-dimensional chemistry-transport model for ruling the Ozone Budget in the Stratosphere (REPROBUS) 

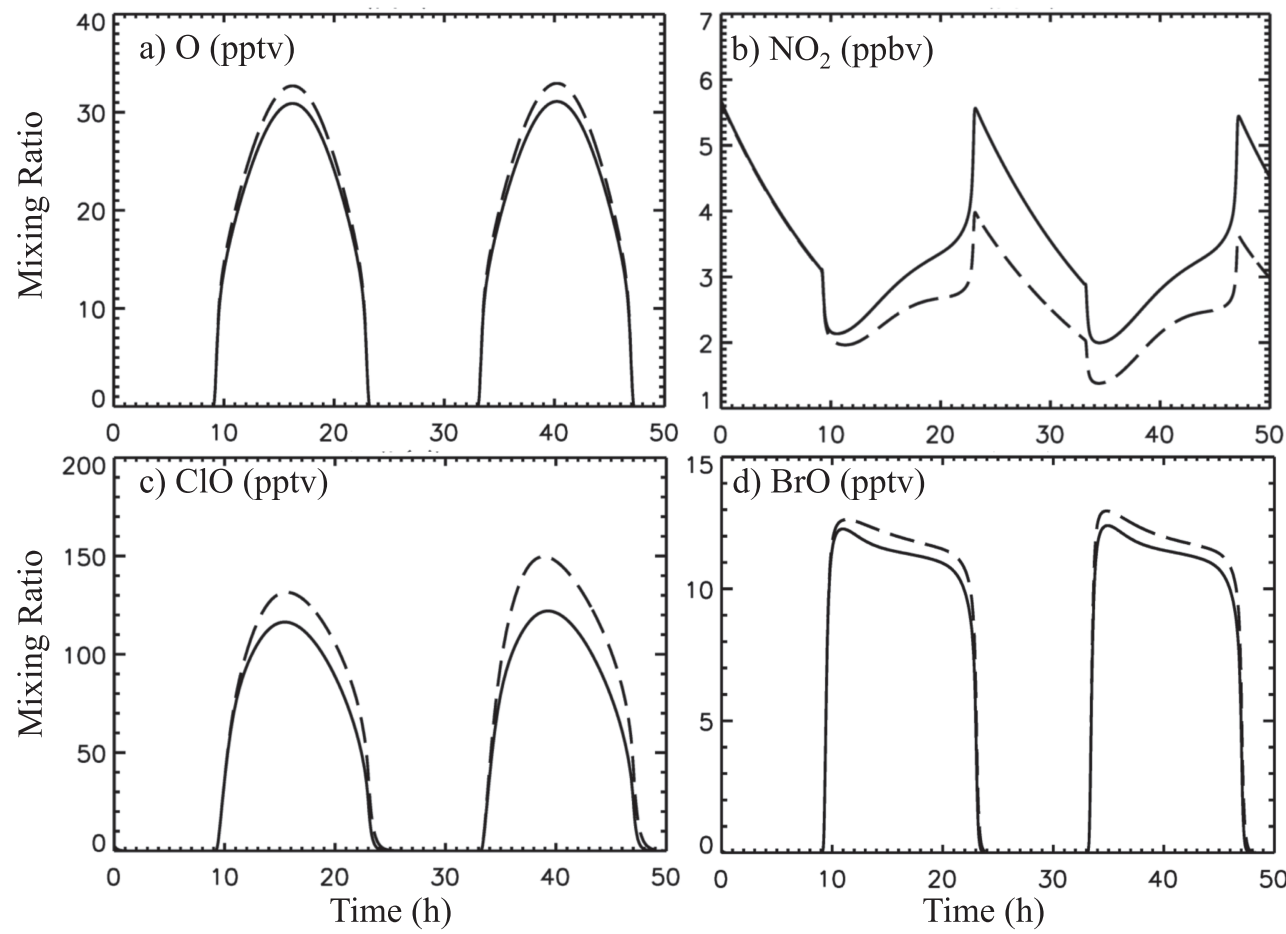

Figure 1. Time evolution of volume mixing ratio of (a) atomic oxygen, (b) $\mathrm{NO}_{2}$, (c) $\mathrm{ClO}$, and (d) $\mathrm{BrO}$ for the representative of oxygen, nitrogen, chlorine, and bromine species, respectively. Rate coefficients of W2015 version is in dotted line and of JPL is in solid line.

Model (Lefèvre et al., 1994, 1998) with daily forecasts on AERIS data center from 0 to $90 \mathrm{~km}$ (http://cds-espri. ipsl.fr/). At $27 \mathrm{~km}$, the atmospheric temperature is $223 \mathrm{~K}$ and the pressure is $19.75 \mathrm{hPa}$ on 22 July 2007.

\section{Model Validation}

This part presents the validation results of neutral chemistry and plasma chemistry by MiPO-Streamer model. All the results are compared to W2015 study to demonstrate the MiPO-Streamer model rationality of neutral chemistry reactions and their rates, and the capability of simulating the impact of BJ streamer chemistry.

\subsection{Neutral Chemistry}

For neutral chemistry validation, we compare obtained results considering JPL reaction and photolysis rates, to those used in W2015. With the same species and set of reactions as W2015, rate coefficients of neutral chemistry in MiPO-Streamer model are based on JPL. The reactions that have different rate coefficients between W2015 and JPL are listed in Table S3. We do not consider any discharge processes in this validation part. The model starts during nighttime ( $~ 8 \mathrm{pm}, \mathrm{LT})$ with a 2-day simulation, using a time step value of $30 \mathrm{~s}$.

Figure 1 shows the time evolution of VMRs of atomic oxygen, $\mathrm{NO}_{2}, \mathrm{ClO}$, and $\mathrm{BrO}$, which are the reactive species in the oxygen, nitrogen, chlorine, and bromine families, respectively. Whatever the version of rate coefficients used, we obtain the same shape of diurnal variations and same order of magnitude for all reactive species. For atomic oxygen, $\mathrm{BrO}$, and $\mathrm{ClO}$, JPL rate coefficients induce a little smaller maximum of VMR (not more than 15\%). For $\mathrm{NO}_{2}$, the VMR simulated is higher with the rate coefficients of JPL as compared to those of W2015 (1.5 ppbv).

The VMR of atomic oxygen with the rate coefficients of JPL is smaller than that of W2015 (Figure 1a), mainly because the rate coefficients of (R1), (R2), (R23), (R24), and (R25) from JPL are larger than those from W2015 (see Table S3). Meanwhile, the larger rate coefficients of (R23), (R24), and (R25) and the smaller rate coefficient of (R43) make more $\mathrm{NO}_{2}$ VMR produced over the 2-day simulation with JPL (Figure 1b). There are 


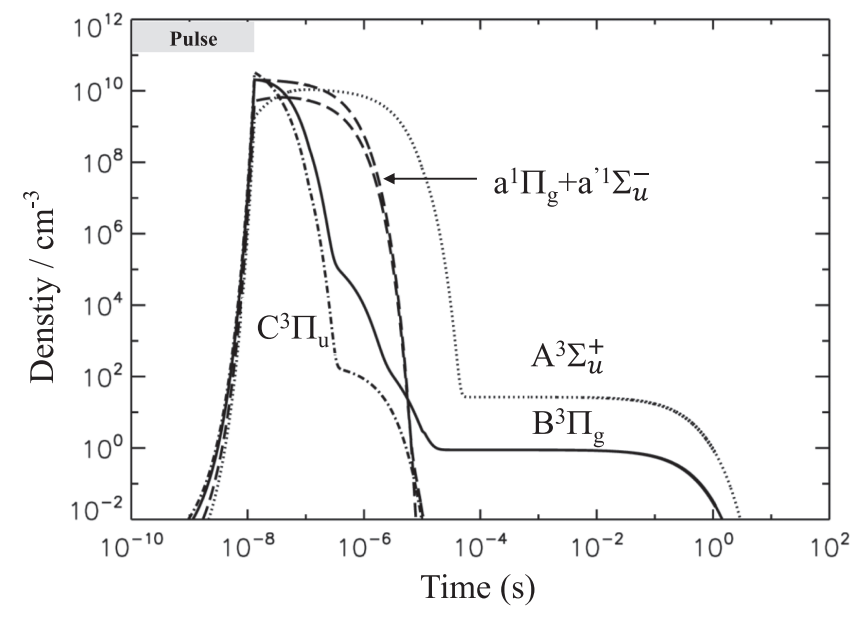

Figure 2. Time evolution of excited molecular nitrogen species at $27 \mathrm{~km}$ when streamer pulse occurs. lower VMRs of $\mathrm{ClO}$ and $\mathrm{BrO}$ in MiPO-Streamer model mainly due to their loss processes by $\mathrm{NO}$ and $\mathrm{NO}_{2}$, such as chemistry reactions:

$$
\begin{gathered}
\mathrm{ClO} / \mathrm{BrO}+\mathrm{NO} \rightarrow \mathrm{Cl} / \mathrm{Br}+\mathrm{NO}_{2}, \\
\mathrm{ClO} / \mathrm{BrO}+\mathrm{NO}_{2} \stackrel{\mathrm{M}}{\rightarrow} \mathrm{ClONO}_{2} / \mathrm{BrONO}_{2}
\end{gathered}
$$

Moreover, the diurnal variation of $\mathrm{NO}_{2}$ with JPL initialization is better in equilibrium than that with W2015, which it is not. Since there is no perturbation factor in this neutral chemistry simulation, the diurnal variation of species should be in equilibrium. As the JPL reaction rate coefficients are used and recommended for chemistry atmospheric models, we consider JPL reaction rates as standard for neutral chemistry.

\subsection{Plasma Chemistry}

For the sake of comparison, in the initialization of the plasma chemistry validation part, we set the initial $n_{e^{-}}$, plasma chemistry reactions, rate coefficients, and BJ streamer starting time (03:12:30 UTC, solar zenith angle $\sim 14^{\circ}$, noon) as in W2015. Moreover, we consider the BJ streamer discharge in MiPO-Streamer model as a boxcar field constant pulse as in W2015.

If we want to compare plasma chemistry and neutral chemistry results to W2015, it is necessary to produce the same $n_{e^{-}}$as W2015. We use the same set of reactions for electric-field-dependant processes as in W2015 and calculate the rate coefficients using BOLSIG+ solver (see Table S4 for details). As the production of electrons is growing exponentially, a small difference in reaction rates leads to a strong change in $n_{e^{-}}$and as a consequence in the production of all excited species. Therefore, to obtain the same maximum $n_{e^{-}}$as in W2015, we adapt the pulse duration. We use a $13.12 \mathrm{~ns}$ pulse (smaller than the one used in W2015, $\sim 50 \mathrm{~ns}$ ) to produce $n_{e^{-}}=5.1204 \times 10^{10} \mathrm{~cm}^{-3}$, similar to $n_{e^{-}}=5.1529 \times 10^{10} \mathrm{~cm}^{-3}$ from W2015 (e.g., see Raizer et al., 2007). Scaled to ground-level, this value of $n_{e^{-}}$is very close to $10^{14} \mathrm{~cm}^{-3}$ (e.g., see Pasko et al., 1998), and hence representation of the electron density in a streamer channel.

As in W2015, during the streamer pulse, the density of excited $\mathrm{N}_{2}$ states increases significantly (Figure 2). They are generated by electron impact excitation, radiative and collisional deactivation, and the rapid decay starts at the end of pulse, which is due to radiative de-excitation, quenching, and chemical reactions. The generated shapes, timescales, and values obtained by MiPO-Streamer model are similar to those of W2015 (see Figure 6 of W2015).

Compared to W2015, the time evoslution of nitrogen species (Figure 3a) shows the same shapes and similar densities for time evolution of $\mathrm{N}\left({ }^{2} \mathrm{D}\right)$ and $\mathrm{N}\left({ }^{2} \mathrm{P}\right)$, due to the following reactions:

$$
\begin{aligned}
& \mathrm{e}^{-}+\mathrm{N}_{2} \rightarrow \mathrm{N}+\mathrm{N}\left({ }^{2} \mathrm{D}\right)+\mathrm{e}^{-}, \\
& \mathrm{e}^{-}+\mathrm{N}_{2} \rightarrow \mathrm{N}+\mathrm{N}\left({ }^{2} \mathrm{P}\right)+\mathrm{e}^{-} .
\end{aligned}
$$

The rapidly increased density of NO after the electric pulse at $10^{-5} \mathrm{~s}$ is caused by the loss of $\mathrm{N}\left({ }^{2} \mathrm{D}\right)$ and $\mathrm{N}\left({ }^{2} \mathrm{P}\right)$ by the reactions:

$$
\begin{aligned}
& \mathrm{N}\left({ }^{2} \mathrm{D}\right)+\mathrm{O}_{2} \rightarrow \mathrm{NO}+\mathrm{O}, \\
& \mathrm{N}\left({ }^{2} \mathrm{P}\right)+\mathrm{O}_{2} \rightarrow \mathrm{NO}+\mathrm{O} .
\end{aligned}
$$

The maximum densities of $\mathrm{NO}$ and $\mathrm{NO}_{2}$ are larger than those obtained by W2015 (maximum density of NO $\sim 6.25 \times 10^{10} \mathrm{~cm}^{-3}$, of $\mathrm{NO}_{2} \sim 3.2 \times 10^{10} \mathrm{~cm}^{-3}$ ) and regarding the maximum density of atomic nitrogen, it is strongly higher $\left(\sim 19.2 \times 10^{10} \mathrm{~cm}^{-3}\right)$ in our simulation compared to W2015 $\left(\sim 2.2 \times 10^{10} \mathrm{~cm}^{-3}\right)$ at $\sim 10^{-8} \mathrm{~s}$. These differences are not due to reactions (1-4) because the maximum densities of $\mathrm{N}\left({ }^{2} \mathrm{D}\right)$ and $\mathrm{N}\left({ }^{2} \mathrm{P}\right)$ are similar to those of W2015. The atomic nitrogen is also produced by the dissociation reaction (5): 

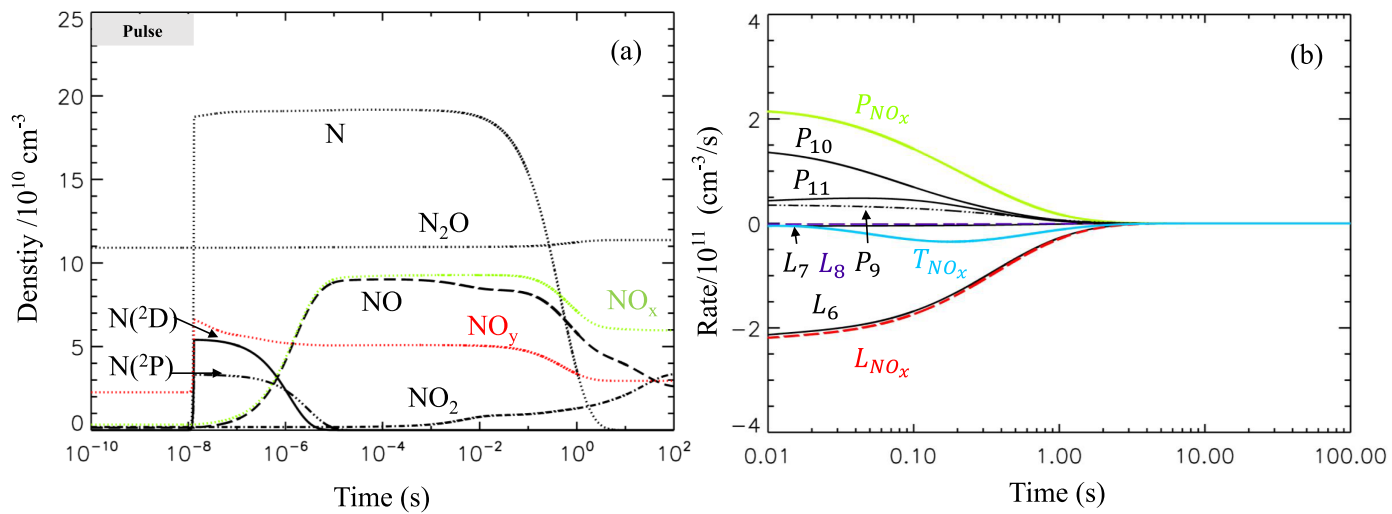

Figure 3. (a) Time evolutions of $\mathrm{NO}$ and other nitrogen radicals at $27 \mathrm{~km}$ when the pulse streamer occurs. The shaded area indicates the time period of the electric pulse. (b) Loss and production rate densities of $\mathrm{NO}_{x}$ associated with reaction (6)-(11) after $10^{-2} \mathrm{~s}$.

$$
\mathrm{N}_{2}+\mathrm{e}^{-} \rightarrow \mathrm{N}+\mathrm{N}+\mathrm{e}^{-}
$$

The rate coefficient at $27 \mathrm{~km}$ with $\theta=600 \mathrm{Td}$ we calculate using BOLSIG+ solver is $4.56 \times 10^{-9} \mathrm{~cm}^{3} / \mathrm{s}$, which value is in between those of André (1997) $\left(\sim 2.31 \times 10^{-10} \mathrm{~cm}^{3} / \mathrm{s}\right)$ and Sentman et al. (2008) $\left(\sim 4.22 \times 10^{-8} \mathrm{~cm}^{3} / \mathrm{s}\right)$.

Note that whatever the rate considered for reaction (5), the density of atomic nitrogen must be greater than the densities of $\mathrm{N}\left({ }^{2} \mathrm{D}\right)$ and $\mathrm{N}\left({ }^{2} \mathrm{P}\right)$ due to reactions (1), (2), and (5), which is not the case in W2015. Feldman and Doering (1975), Rees and Jones (1973), and Doering et al. (1975) also reported higher density of atomic nitrogen compared to the densities of $\mathrm{N}\left({ }^{2} \mathrm{D}\right)$ and $\mathrm{N}\left({ }^{2} \mathrm{P}\right)$. The large difference in atomic nitrogen density is due to reaction (5).

As in W2015, atomic nitrogen density starts to decrease after $0.01 \mathrm{~s}$ mainly due to the following reactions:

$$
\begin{gathered}
\mathrm{N}+\mathrm{NO} \rightarrow \mathrm{O}+\mathrm{N}_{2}, \\
\mathrm{~N}+\mathrm{NO}_{2} \rightarrow \mathrm{O}+\mathrm{N}_{2} \mathrm{O}, \\
\mathrm{N}+\mathrm{NO}_{2} \rightarrow \mathrm{O}+\mathrm{O}+\mathrm{N}_{2}, \\
\mathrm{~N}+\mathrm{O}_{2} \rightarrow \mathrm{NO}+\mathrm{O} .
\end{gathered}
$$

These reactions lead to the production of atomic oxygen (6-9) and $\mathrm{NO}(9)$, the loss of $\mathrm{NO}, \mathrm{NO}_{2}(6-8)$. The loss in atomic nitrogen is also associated with the reactions related to $\mathrm{HO}_{x}$ (odd hydrogen family) (10) and (11), which produce NO:

$$
\begin{gathered}
\mathrm{N}+\mathrm{OH} \rightarrow \mathrm{NO}+\mathrm{H}, \\
\mathrm{N}+\mathrm{HO}_{2} \rightarrow \mathrm{NO}+\mathrm{OH} .
\end{gathered}
$$

Figure $3 \mathrm{~b}$ presents the time evolution of production and loss rates of $\mathrm{NO}_{x}$ associated with reactions (6-11) after $0.01 \mathrm{~s}$. Among reactions (6), (9), (10), and (11), the total loss rate of $\mathrm{NO}_{x}$ is $L_{\mathrm{NO}_{x}}=-\left(L_{6}+L_{7}+L_{8}\right)$ (in red), the total produced rate of $\mathrm{NO}_{x}$ is $P_{\mathrm{NO}_{x}}=P_{9}+P_{10}+P_{11}$ (in green), and the net rate of $\mathrm{NO}_{x}$ is $T_{\mathrm{NO}_{x}}=P_{\mathrm{NO}_{x}}+L_{\mathrm{NO}_{x}}$ (in blue). The major production of $\mathrm{NO}_{x}$ is due to reactions (9-11) and loss of $\mathrm{NO}_{x}$ due to (6). The net rate value of $\mathrm{NO}_{x}$ is negative from 0.01 to $2 \mathrm{~s}$; it corresponds to the decrease of $\mathrm{NO}_{x}$ during the same period in Figure 3a. After $2 \mathrm{~s}, T_{\mathrm{NO}_{x}}$ is equal to zero.

The time evolution of densities of ground state atomic oxygen, excited state $\mathrm{O}\left({ }^{1} \mathrm{~S}\right)$, and the $\mathrm{O}_{3}$ change by discharge $\left(\Delta \mathrm{O}_{3}\right)$ (Figure $4 \mathrm{a}$ ) present also a similar shape as in W2015. The density of atomic oxygen produced through electric field-driven processes are slightly larger in our simulation $\left(\sim 3.7 \times 10^{11} \mathrm{~cm}^{-3}\right)$ than in W2015 $\left(\sim 3.2 \times 10^{11} \mathrm{~cm}^{-3}\right)$. It is mostly due to the small difference on the rate coefficients of electric field-driven 

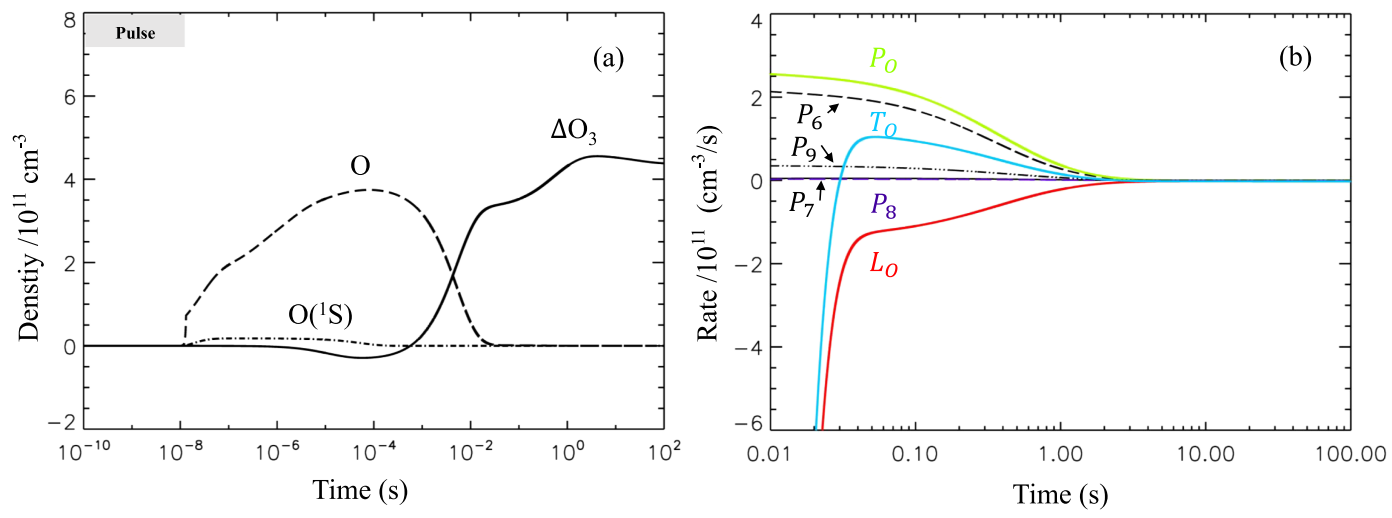

Figure 4. (a) Time evolution densities of ground state atomic oxygen and excited $\mathrm{O}\left({ }^{1} \mathrm{~S}\right), \Delta \mathrm{O}_{3}$ at $27 \mathrm{~km}$. The shaded area indicates the time period of the electric pulse. (b) Loss and production rate densities of atomic oxygen associated with reaction (6)-(11) after $10^{-2} \mathrm{~s}$.

process reactions. The negative density value of $\Delta \mathrm{O}_{3}$ occurs around $10^{-8} \mathrm{~s}$, due to the increasing density of $\mathrm{O}\left({ }^{1} \mathrm{~S}\right)$ by reactions:

$$
\begin{gathered}
\mathrm{O}\left({ }^{1} \mathrm{~S}\right)+\mathrm{O}_{3} \rightarrow \mathrm{O}_{2}+\mathrm{O}_{2}, \\
\mathrm{O}\left({ }^{1} \mathrm{~S}\right)+\mathrm{O}_{3} \rightarrow \mathrm{O}\left({ }^{1} \mathrm{D}\right)+\mathrm{O}+\mathrm{O}_{2} .
\end{gathered}
$$

The density of $\Delta \mathrm{O}_{3}$ starts to increase at $10^{-4} \mathrm{~s}$ when the atomic oxygen density decreases through

$$
\mathrm{O}+\mathrm{O}_{2} \stackrel{\mathrm{M}}{\rightarrow} \mathrm{O}_{3}
$$

The density of $\Delta \mathrm{O}_{3}$ shows a similar behavior as W2015 until all the atomic oxygen have been consumed at $\sim 0.01 \mathrm{~s}$. After then, the density of $\Delta \mathrm{O}_{3}$ increases quickly until $\sim 3 \mathrm{~s}$. Maximum density of $\Delta \mathrm{O}_{3}$ obtained in our study $\left(\sim 4.56 \times 10^{11} \mathrm{~cm}^{-3}\right)$ is larger than in W2015 $\left(\sim 2.9 \times 10^{11} \mathrm{~cm}^{-3}\right)$, and the maximum density of $\Delta \mathrm{O}_{3}$ is larger than that of atomic oxygen produced during the discharge. Figure $4 \mathrm{~b}$ presents the time evolution of production and loss rates of atomic oxygen associated with reactions (6-9) after $0.01 \mathrm{~s}$. The total production rate of atomic oxygen is $P_{\mathrm{O}}=P_{6}+P_{7}+2 \times P_{8}+P_{9}$ (in green), and the total loss rate of atomic oxygen is $L_{\mathrm{O}}=L_{14}$ (in red) and the net rate of atomic oxygen is $T_{\mathrm{O}}=P_{O}+L_{O}$ (in blue). The net rate value of atomic oxygen is positive from 0.03 to $3 \mathrm{~s}$, it corresponds to the increase of $\Delta \mathrm{O}_{3}$ density during the same period, as seen in Figure 4a. It means that the $\Delta \mathrm{O}_{3}$ density produced in this part is mainly due to reactions (6-9) with atomic nitrogen, which can produce atomic oxygen. Because of reactions (10) and (11), the produced $\Delta \mathrm{O}_{3}$ density from 0.03 to $3 \mathrm{~s}\left(1 \times 10^{11} \mathrm{~cm}^{-3}\right)$ is smaller than the consumed atomic nitrogen density $\left(1.9 \times 10^{11} \mathrm{~cm}^{-3}\right)$. When all the atomic nitrogen has been consumed, $\mathrm{O}_{3}$ density decreases slowly from $3 \mathrm{~s}$ by reaction with nitric oxide (see Figure 4 a):

$$
\mathrm{O}_{3}+\mathrm{NO} \rightarrow \mathrm{O}_{2}+\mathrm{NO}_{2}
$$

As displayed above, the plasma chemistry validation results of MiPO-Streamer model show a good agreement in shape but not in density when compared to W2015 (Table 1). Investigating in detail the set of reaction, it appears that the atomic nitrogen production is critical for both $\mathrm{NO}_{x}$ and $\mathrm{O}_{3}$ production.

\section{Investigation of the Impact of the Electric Field Time-Profile}

In this part, we perform a comparison of results obtained using a simple electrical field pulse (pulse simulation) and the electric field time evolution, derived from an electrodynamic streamer model (Ihaddadene \& Celestin, 2017), to represent the streamer. 
Table 1

Maximum Densities of Electron $\left(e^{-}\right), \mathrm{N}_{2}\left(\mathrm{~A}^{3} \sum_{\mathrm{u}}^{+}\right)$, Atomic Oxygen $(\mathrm{O}), \mathrm{O}\left({ }^{1} \mathrm{~S}\right), \Delta \mathrm{O}_{3}$, Atomic Nitrogen $(\mathrm{N}), \mathrm{N}\left({ }^{2} \mathrm{D}\right), \mathrm{N}\left({ }^{2} \mathrm{P}\right), \mathrm{NO}$, and $\mathrm{NO} \mathrm{O}_{2}$ Obtained at 27 km from the W2015 During the First $100 \mathrm{~s}$, and from the MiPO-Streamer During the First $100 \mathrm{~s}$ and at $48 \mathrm{hr}$

\begin{tabular}{|c|c|c|c|c|c|c|c|c|c|c|c|}
\hline \multirow[b]{2}{*}{ Timescale } & \multirow[b]{2}{*}{ Pulse model } & \multicolumn{10}{|c|}{ Maximum density $\times 10^{10}\left(\mathrm{~cm}^{-3}\right)$} \\
\hline & & $\mathrm{e}^{-}$ & $\mathrm{N}_{2}\left(\mathrm{~A}^{3} \sum_{\mathrm{u}}^{+}\right)$ & $\mathrm{O}$ & $\mathrm{O}\left({ }^{1} \mathrm{~S}\right)$ & $\Delta \mathrm{O}_{3}$ & $\mathrm{~N}$ & $\mathrm{~N}\left({ }^{2} \mathrm{D}\right)$ & $\mathrm{N}\left({ }^{2} \mathrm{P}\right)$ & NO & $\mathrm{NO}_{2}$ \\
\hline \multirow[t]{2}{*}{ During the first $100 \mathrm{~s}$} & W2015 & 5.15 & 5 & 31.5 & 3 & 29 & 2.2 & 3.8 & 2.3 & 6.2 & 3.2 \\
\hline & MiPO-Streamer & 5.12 & 2 & 37.5 & 2 & 45.5 & 19 & 5.4 & 3.5 & 9 & 3.4 \\
\hline At $48 \mathrm{hr}$ & MiPO-Streamer & 0 & 0 & 0 & 0 & -30 & 0 & 0 & 0 & 0 & 2.2 \\
\hline
\end{tabular}

\subsection{Initialization}

Most of BJs are observed at night when convective clouds are in mature stage (e.g., Chanrion et al., 2017; Chou et al., 2011). Therefore, simulations are performed during nighttime starting at zenith angle of $104^{\circ}$. The initial $n_{e^{-}}$used is $n_{e^{-}}=1.7 \times 10^{13} \mathrm{~N}^{-1} \mathrm{~cm}^{-3}, \mathrm{~N}$ is the local air density (Mitchell \& Hale, 1973; MacGorman \& Rust, 1998, p. 34). As in previous paragraphs, we focus in the middle stratosphere at $27 \mathrm{~km}$ where reactive nitrogen interacts strongly with ozone.

\subsection{Reduced Electric Field}

Both electrical field time evolutions considered are presented in Figure 5a. For the pulse simulation case, the reduced electrical field $\theta=600 \mathrm{Td}$ is considered during $15.57 \mathrm{~ns}$ (stage $P_{\mathrm{i}}$, solid line) and then $\theta=0 \mathrm{Td}$ (stage $P_{\mathrm{ii}}$, dotted line). In the case with field obtained from streamer simulation, the electric field shows a light increase during $60 \mathrm{~ns}$ and then a strong increase up to $773.08 \mathrm{Td}$. The duration of this stage (called $S_{\mathrm{i}}$, solid line) is $78.3 \mathrm{~ns}$. Then, the field decreases exponentially down to $52 \mathrm{Td}$ during $7.9 \mathrm{~ns}$ ( $S_{\mathrm{ii}}$ stage, dash-dot line $)$, and then $\theta=0$ ( $S_{\mathrm{iii}}$ stage, dotted line). The total duration of the electrical field perturbation due to the streamer is $86.2 \mathrm{~ns}$.

As in the previous part, we adapt the duration time of pulse simulation to get a similar $n_{e^{-}}$(Figure 5b) as obtained in streamer simulation (streamer simulation $n_{e^{-}}$is $8.56289 \times 10^{10} \mathrm{~cm}^{-3}$ and pulse simulation $n_{e^{-}}$ is $\left.8.48007 \times 10^{10} \mathrm{~cm}^{-3}\right)$. The decreases of $n_{e^{-}}$from two simulations occur at the same time $\left(\sim 10^{-8} \mathrm{~s}\right)$ and are quite similar for both simulations.

\subsection{Results During the First $100 \mathrm{~s}$}

Results obtained for $\mathrm{N}_{2}$ excited species, atomic oxygen and atomic nitrogen reactive species with both parameterization pulse simulation and streamer simulation, are presented in Figure 6 during the first $100 \mathrm{~s}$.

For densities of excited $\mathrm{N}_{2}$ (Figure 6a), their time evolutions are roughly similar except for the small delay for the maximum production of each species in streamer simulation, which comes from the delay of electron productions (Figure 5b). The de-excitation of $\mathrm{N}_{2}$ excited species with density values lower than $10^{-10} \mathrm{~cm}^{-3}$
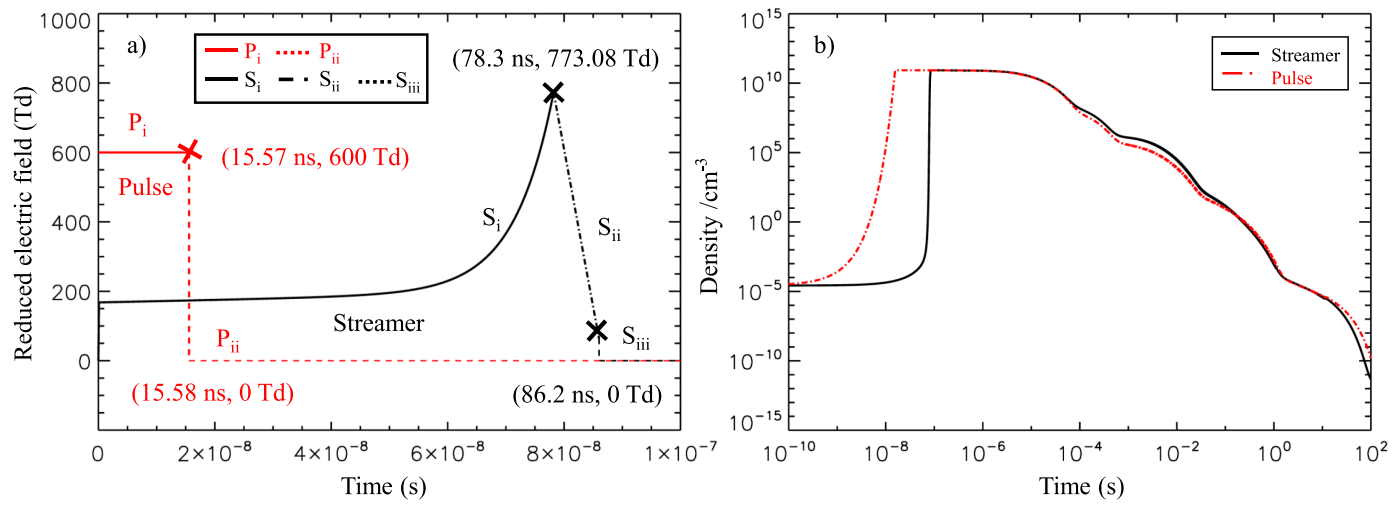

Figure 5. At $27 \mathrm{~km}$, time evolution of (a) reduced electrical field $\theta(\mathrm{Td}),(\mathrm{b})$ electron densities $\left(\mathrm{n}_{\mathrm{e}^{-}}, \mathrm{cm}^{-3}\right)$ with the pulse and simulated streamer cases, respectively, in red and black. 

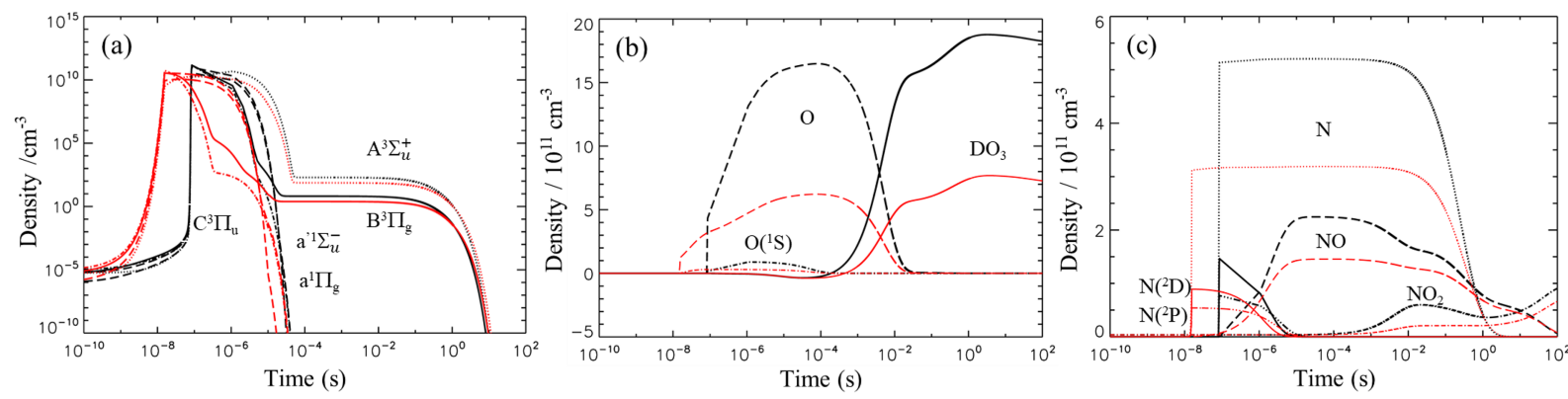

Figure 6. Time evolutions in $100 \mathrm{~s}$ for (a) excited $\mathrm{N}_{2}$, (b) oxygen, (c) nitrogen family at $27 \mathrm{~km}$ from streamer simulation (in black) and pulse simulation (in red). The same line style in each graph indicates the same species.

occurs in either simulation cases at $10^{-5}-10^{-4} \mathrm{~s}$ for $\mathrm{N}_{2}\left(\mathrm{~A}^{\prime 1} \sum_{\mathrm{u}}^{-}\right)$and $\mathrm{N}_{2}\left(\mathrm{a}^{1} \prod_{\mathrm{g}}\right)$, and at $10 \mathrm{~s}$ for $\mathrm{N}_{2}\left(\mathrm{~A}^{3} \sum_{\mathrm{u}}^{+}\right)$and $\mathrm{N}_{2}\left(\mathrm{~B}^{3} \prod_{\mathrm{g}}\right)$.

For atomic oxygen and atomic nitrogen species (Figures $6 \mathrm{~b}$ and $6 \mathrm{c}$ ), the similar small delay for production of atomic oxygen, $\mathrm{O}\left({ }^{1} \mathrm{~S}\right), \mathrm{N}\left({ }^{2} \mathrm{D}\right)$, and $\mathrm{N}\left({ }^{2} \mathrm{P}\right)$ by streamer simulation is observed, but each time evolution presents roughly the same shape. Surprisingly, stronger density productions of atomic oxygen, $\mathrm{O}\left({ }^{1} \mathrm{~S}\right), \mathrm{N}\left({ }^{2} \mathrm{D}\right)$, atomic nitrogen, $\mathrm{NO}$, and $\mathrm{NO}_{2}$ with the streamer simulation are obtained compared to pulse simulation.

The maximum density values of electron, $\mathrm{N}_{2}\left(\mathrm{~A}^{3} \sum_{\mathrm{u}}^{+}\right)$, atomic oxygen, $\mathrm{O}\left({ }^{1} \mathrm{~S}\right), \Delta \mathrm{O}_{3}$, atomic nitrogen, $\mathrm{N}\left({ }^{2} \mathrm{D}\right)$, $\mathrm{N}\left({ }^{2} \mathrm{P}\right), \mathrm{NO}$, and $\mathrm{NO}_{2}$ for both simulations are reported in Table 2 . Whereas the electron densities produced are similar for both simulations, the maximum density values of $\mathrm{N}_{2}\left(\mathrm{~A}^{3} \sum_{\mathrm{u}}^{+}\right)$, atomic oxygen, $\mathrm{O}\left({ }^{1} \mathrm{~S}\right), \mathrm{N}\left({ }^{2} \mathrm{D}\right)$, and $\left.\mathrm{N}^{2} \mathrm{P}\right)$ are multiplied by a factor $\sim 2$ for the realistic streamer simulation case as compared to the pulse simulation case. This impact directly enhances the densities of $\mathrm{O}_{3}$ and $\mathrm{NO}_{x}\left(\mathrm{NO}\right.$ and $\left.\mathrm{NO}_{2}\right)$. After $100 \mathrm{~s}$, the $\mathrm{O}_{3}$ density is higher by a factor of two, and $\mathrm{NO}_{2}$ density by a factor of 1.5 , in the streamer simulation case as compared to pulse simulation case (Figures $6 \mathrm{~b}$ and $6 \mathrm{c}$ ).

\subsection{Results in the 2-Day Simulations}

The perturbations of atomic oxygen, $\mathrm{NO}_{2}, \mathrm{ClO}$, and $\mathrm{BrO}$ reactive species impacted by streamer discharge during 2 days at $27 \mathrm{~km}$ are analyzed in this part, as well as the time evolution of $\mathrm{O}_{3}$.

Figure 7 shows the time evolution of atomic oxygen, $\mathrm{NO}_{2}, \mathrm{ClO}$, and $\mathrm{BrO}$ VMRs during 2 days with streamer simulation in black, pulse simulation in red and a no-discharge simulation case in blue. These four reactive species present classical diurnal variation with maximum VMRs at noon for atomic oxygen, $\mathrm{ClO}$, and $\mathrm{BrO}$, and at night for $\mathrm{NO}_{2}$.

Figure 7a shows that the first-day maximum VMR of atomic oxygen with the streamer simulation is $45 \mathrm{pptv}$, 37 pptv for the pulse simulation and 31 pptv for the no-discharge simulation case. The additional atomic oxygen VMRs exist in both discharge simulations. On the second day, the atomic oxygen VMRs with streamer and pulse simulations decrease and they have no significant difference from the no-discharge case (streamer simulation $\sim 38$ pptv, pulse simulation $\sim 32 \mathrm{pptv}$ ). The reactive atomic oxygen has short lifetime, and the perturbation of the atomic oxygen VMR time evolution for streamer simulation is a little bit longer than that for pulse simulation. Figure $7 \mathrm{~b}$ shows the simulations just after discharge strongly increase the $\mathrm{NO}_{2}$ VMR (maximum VMR of $\mathrm{NO}_{2} \sim 150 \mathrm{ppbv}$ by streamer simulation, $\sim 115$ ppbv by pulse simulation). The produced $\mathrm{NO}_{2} \mathrm{VMR}$ is 20-30 times compared to that in the no-discharge simulation case (maximum $\mathrm{VMR}$ of $\mathrm{NO}_{2} \sim 5.5 \mathrm{ppbv}$ ), and this enhancement of $\mathrm{NO}_{2} \mathrm{VMR}$ is maintained during the 2-day simulation. The maximum VMRs of $\mathrm{O}$ and $\mathrm{NO}_{2}$ decrease day by day. The discharge simulations cause non-equilibrium in the neutral gases system (see Figure 1). It means that the excess of $\mathrm{O}$ and $\mathrm{NO}_{2} \mathrm{VMRs}$ due to discharge are available for chemistry.

Figure $7 \mathrm{c}$ shows that the maximum VMRs at noon ( 16 hr after the discharge occurred) of ClO from the discharge simulations (streamer simulation $\sim 7 \mathrm{pptv}$, pulse simulation $\sim 9 \mathrm{pptv}$ ) are strongly lower than that in the no-discharge simulation case ( 120 pptv). BrO also showed less VMR maximum from the discharge 
Table 2

Maximum Densities of Electron $\left(e^{-}\right), \mathrm{N}_{2}\left(\mathrm{~A}^{3} \sum_{\mathrm{u}}^{+}\right)$, Atomic Oxygen $(\mathrm{O}), \mathrm{O}\left({ }^{1} \mathrm{~S}\right), \Delta \mathrm{O}_{3}$, Atomic Nitrogen $(\mathrm{N}), \mathrm{N}\left({ }^{2} \mathrm{D}\right), \mathrm{N}\left({ }^{2} \mathrm{P}\right), \mathrm{NO}$, and $\mathrm{NO}_{2}$ Obtained in the Pulse Simulation Case and in the Streamer Simulation Case at $27 \mathrm{~km}$

\begin{tabular}{|c|c|c|c|c|c|c|c|c|c|c|}
\hline $\begin{array}{l}\text { Maximum density } \\
10^{11}\left(\mathrm{~cm}^{-3}\right)\end{array}$ & $\mathrm{e}^{-}$ & $\mathrm{N}_{2}\left(\mathrm{~A}^{3} \sum_{\mathrm{u}}^{+}\right)$ & $\mathrm{O}$ & $\mathrm{O}\left({ }^{1} \mathrm{~S}\right)$ & $\Delta \mathrm{O}_{3}$ & $\mathrm{~N}$ & $\mathrm{~N}\left({ }^{2} \mathrm{D}\right)$ & $\mathrm{N}\left({ }^{2} \mathrm{P}\right)$ & NO & $\mathrm{NO}_{2}$ \\
\hline Pulse simulation & 0.85 & 0.18 & 6.22 & 0.3 & 7.69 & 3.19 & 0.89 & 0.54 & 1.45 & 0.74 \\
\hline Streamer simulation & 0.86 & 0.47 & 16.48 & 0.89 & 18.77 & 5.21 & 1.46 & 0.77 & 2.25 & 0.96 \\
\hline
\end{tabular}

simulations ( 2.5 pptv for streamer simulation and $\sim 2.9 \mathrm{pptv}$ for pulse simulation) than from the no-discharge simulation ( 12.5 pptv) (Figure 7d). There is no significant difference in terms of $\mathrm{ClO}$ and BrO VMRs values between streamer and pulse simulation results. The difference between discharge simulations and the no-discharge simulation is caused by the excess of $\mathrm{NO}_{2}$ VMR production (Figure 7b), which leads to the production of reservoirs species $\mathrm{ClONO}_{2}$ and $\mathrm{BrONO}_{2}$ through the following reactions:

$$
\begin{aligned}
& \mathrm{ClO}+\mathrm{NO}_{2} \stackrel{\mathrm{M}}{\rightarrow} \mathrm{ClONO}_{2}, \\
& \mathrm{BrO}+\mathrm{NO}_{2} \stackrel{\mathrm{M}}{\rightarrow} \mathrm{BrONO}_{2} .
\end{aligned}
$$

The VMRs of $\mathrm{ClONO}_{2}$ and $\mathrm{BrONO}_{2}$ at noon (the maximum value during daytime) in the discharge simulations are larger than those in the no-discharge simulation ( 200 pptv for $\mathrm{ClONO}_{2}$ and $\sim 9$ pptv for $\mathrm{BrONO}_{2}$ ).

The perturbation in $\mathrm{O}_{3}$ VMR during the 2-day simulation is shown in Figure 8. The variation of $\mathrm{O}_{3}$ in the streamer simulation case just after the discharge is shown in black, the pulse simulation is in red, and the no-discharge case is in blue. The increased $\mathrm{O}_{3}$ VMRs at the end of discharge (streamer simulation $\sim 9.9$ ppmv,
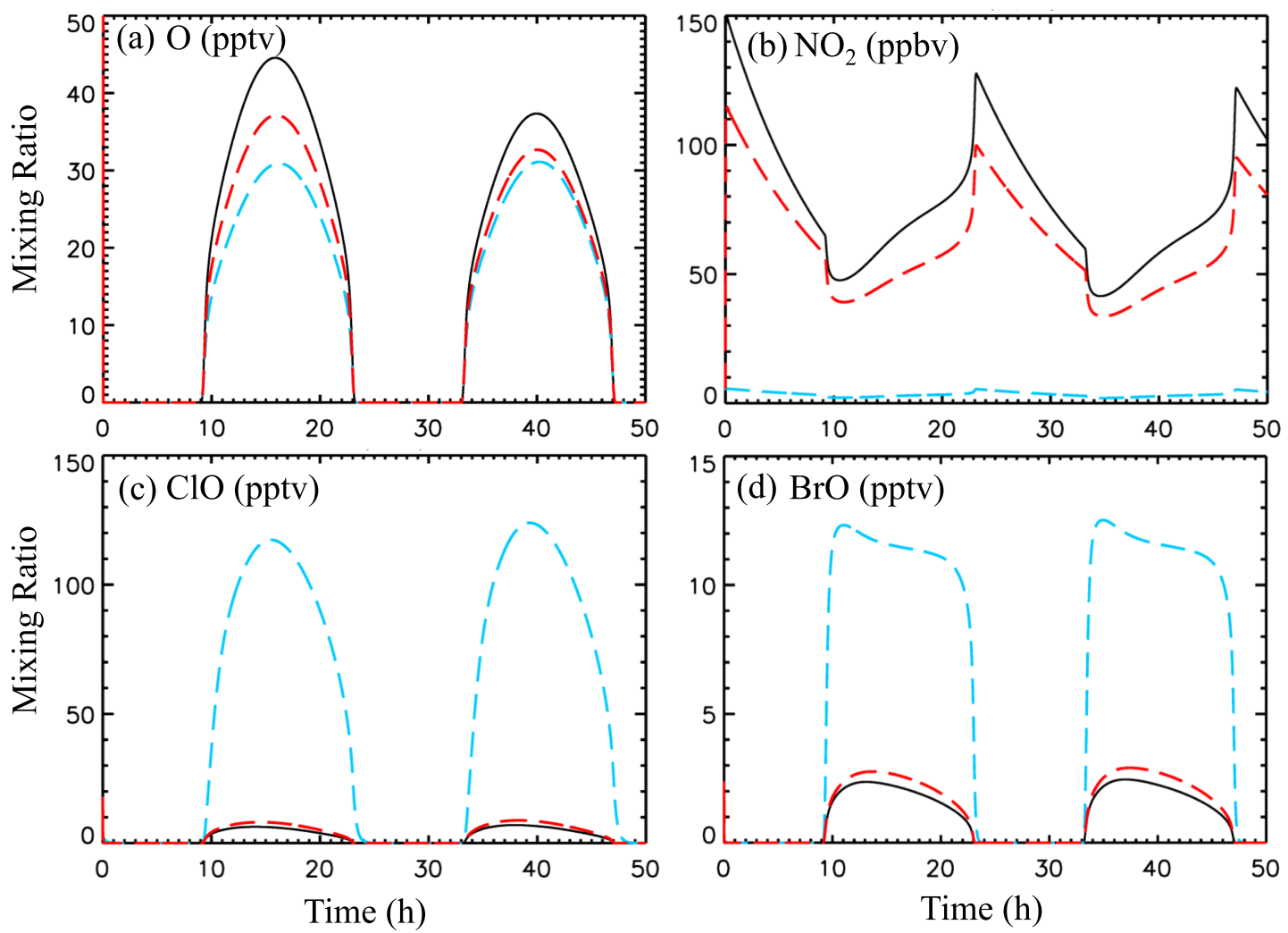

Figure 7. Two-day evolutions of VMRs of (a) atomic oxygen, (b) $\mathrm{NO}_{2}$, (c) ClO, and (d) BrO at $27 \mathrm{~km}$ with streamer simulation (in black solid line), pulse simulation (in red dashed line), and the no-discharge simulation case (in blue dashed line). 


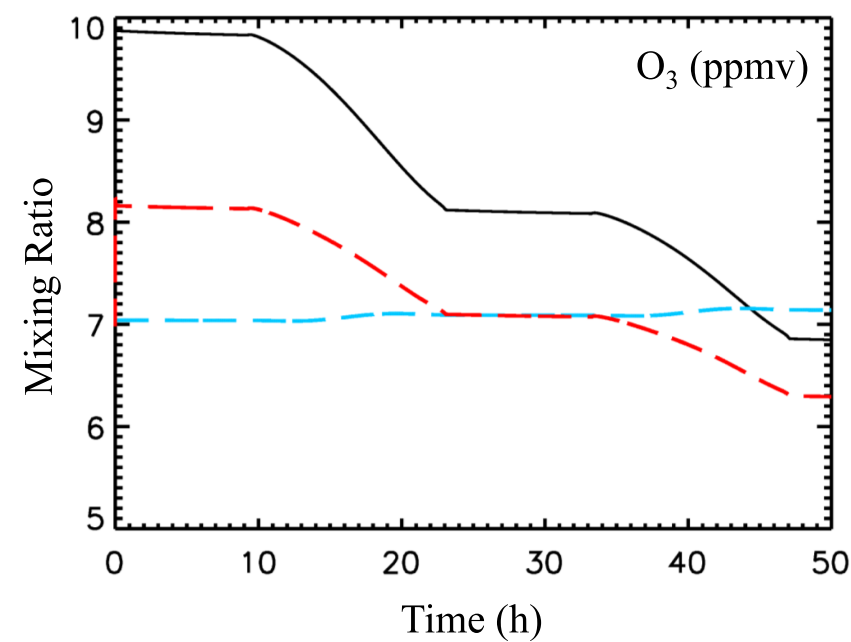

Figure 8. Same as Figure 7, but for ozone. pulse simulation $\sim 8.2 \mathrm{ppmv}$ ) are compared to $\sim 7 \mathrm{ppmv}$ with no-discharge simulation. Due to the discharge, $\mathrm{O}_{3}$ VMR is increased as a first step.

Concerning the time evolution during 2-day simulation, $\mathrm{O}_{3}$ VMRs with streamer and pulse simulations stay constant during the night and decrease during the day. The large amount of $\mathrm{NO}_{x}$ produced by the discharge (Figure 7b) leads to the associated catalytic cycle in stratosphere (Brasseur and Solomon, 1986), which is the main mechanism of $\mathrm{O}_{3}$ destruction in the middle stratosphere (here at $27 \mathrm{~km}$ ) (Portmann et al., 2012). Due to neutral chemistry associated with $\mathrm{NO}_{x}$ production, the enhanced $\mathrm{O}_{3}$ VMRs caused by the discharge are consumed in the 2-day simulations (45 hr for streamer simulation, $34 \mathrm{hr}$ for pulse simulation). After 2 days, $\mathrm{O}_{3}$ VMR in discharge simulations are lower compared to the no-discharge simulation case. The loss of $\mathrm{O}_{3}$ due to the discharge for the pulse simulation is lighter than that for the streamer simulation.

\section{Discussion}

As seen in the previous section, the time profiles of two types of electric fields have an effect on the oxygen, and nitrogen production through the production and heating of electrons. To investigate the differences obtained, as the two simulations had the same maximum $n_{e^{-}}$, we plot density correlations between $\mathrm{N}_{2}\left(\mathrm{~A}^{3} \sum_{\mathrm{u}}^{+}\right)$, atomic nitrogen $(\mathrm{N})$, atomic oxygen $(\mathrm{O})$, and electrons in Figure 9, and represent the different sequences of the field evolution (three stages for the simulation-derived streamer, and two stages for the pulse case; see Figure 5a).

Figure 9 shows the density correlations between $\mathrm{N}_{2}\left(\mathrm{~A}^{3} \sum_{\mathrm{u}}^{+}\right)$, atomic oxygen, and nitrogen, and electron with streamer simulation in black and pulse simulation in red. The correlation between the densities of $\mathrm{N}_{2}$ $\left(\mathrm{A}^{3} \sum_{\mathrm{u}}^{+}\right)$and electrons (Figures $9 \mathrm{a}$ and $9 \mathrm{~b}$ ), and densities of $\mathrm{N}_{2}\left(\mathrm{~A}^{3} \sum_{\mathrm{u}}^{+}\right)$in the simulation-derived streamer case is lower than that obtained in the pulse case at the end of $S_{\mathrm{i}}$ (the raising streamer field stage). At this point, the two simulations corresponded to the same $n_{e^{-}} \sim 10^{6} \mathrm{~cm}^{-3}$.

As the decrease part of streamer field $\left(S_{\mathrm{ii}}\right)$ continues to produce $\mathrm{N}_{2}\left(\mathrm{~A}^{3} \sum_{\mathrm{u}}^{+}\right)$and heat electrons, $\mathrm{N}_{2}\left(\mathrm{~A}^{3} \sum_{\mathrm{u}}^{+}\right)$ density of streamer simulation is larger than that in the pulse simulation case when the two simulations obtain a similar maximum $n_{e^{-}}$. In order to look at the details close to the maximum of $\mathrm{N}_{2}\left(\mathrm{~A}^{3} \sum_{\mathrm{u}}^{+}\right)$density and explain the difference, we plot the correlation in linear scale (Figure 9b). After $n_{e^{-}}$reaches its maximum, $\mathrm{N}_{2}\left(\mathrm{~A}^{3} \sum_{\mathrm{u}}^{+}\right)$density continues to increase for both simulations, whereas the field starts to decrease $\left(S_{\mathrm{ii}}\right.$ and $\left.P_{\mathrm{ii}}\right)$. For both simulations, $n_{e^{-}}$does not decrease directly with the decreasing field, due to the set of reactions of associative and penning ionization:

$$
\mathrm{N}_{2}\left(\mathrm{a}^{\prime 1} \Sigma_{\mathrm{u}}^{-}\right)+\mathrm{N}_{2}\left(\mathrm{~A}^{3} \Sigma_{\mathrm{u}}^{+}\right) \rightarrow \mathrm{e}^{-}+\mathrm{N}_{4}^{+}
$$

This is also due to the characteristic time of

$$
\mathrm{e}^{-}+\mathrm{O}_{2} \rightarrow \mathrm{O}^{-}+\mathrm{O}
$$

Moreover, a delay between excited electronic states and the maximum of $n_{e^{-}}$in the streamer head has been demonstrated by Celestin and Pasko (2010) and predicted by Naidis (2009). This is caused by the following reaction:

$$
\mathrm{e}^{-}+\mathrm{N}_{2} \rightarrow \mathrm{e}^{-}+\mathrm{N}_{2}\left(\mathrm{~A}^{3} \Sigma_{\mathrm{u}}^{+}\right)
$$

which maintains the $\mathrm{N}_{2}\left(\mathrm{~A}^{3} \sum_{\mathrm{u}}^{+}\right)$production density. Moreover, in simulation-derived streamer field, the increase of $\mathrm{N}_{2}\left(\mathrm{~A}^{3} \sum_{\mathrm{u}}^{+}\right)$density at the end of $S_{\mathrm{ii}}(\theta>0 \mathrm{Td})$ is partly impacted by the decreasing electric field. After reaching a maximum in $\mathrm{N}_{2}\left(\mathrm{~A}^{3} \sum_{\mathrm{u}}^{+}\right)$density, simulation-derived streamer field maintains higher $\mathrm{N}_{2}$ $\left(\mathrm{A}^{3} \sum_{\mathrm{u}}^{+}\right)$density than that in pulse simulation. The maximum value of $\mathrm{N}_{2}\left(\mathrm{~A}^{3} \sum_{\mathrm{u}}^{+}\right)$density from 

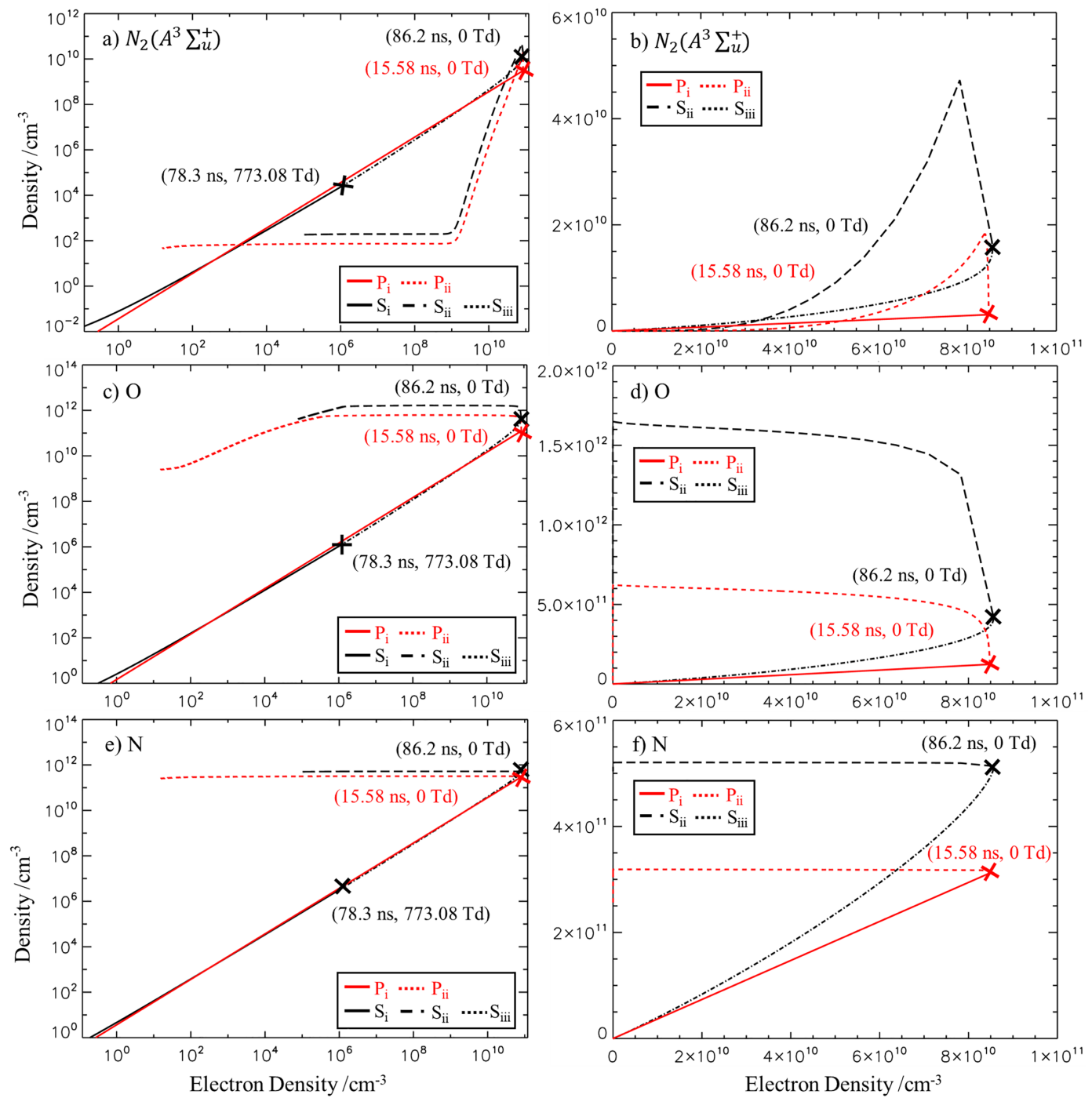

Figure 9. Density correlations between $\mathrm{N}_{2}\left(\mathrm{~A}^{3} \sum_{\mathrm{u}}^{+}\right)$, atomic oxygen and nitrogen to electron. Densities for the case of field derived from electrodynamic simulations are shown in black and in red for the pulse simulation. Among them, (a), (c), and (e) are in log-log scale and (b), (d), and (f) are in linear scale. The sequences of the field are indicated by line-style as in Figure 5a. The crosses indicate the transitions of electric field stages.

simulation-derived streamer field is approximately three times larger than that from pulse simulation (as Table 2 showed). The correlations for density of atomic oxygen and nitrogen to $n_{e^{-}}$(Figures $9 \mathrm{c}$ and $9 \mathrm{e}$ ) are similar to $\mathrm{N}_{2}\left(\mathrm{~A}^{3} \sum_{\mathrm{u}}^{+}\right)$density. The density of atomic nitrogen only depends on field, and there is no delay in the production of atomic nitrogen, since there is no related associative and penning ionization reaction.

\section{Summary and Conclusions}

We developed a new plasma chemistry model named the MiPO-Streamer model. It includes 117 species and 1,760 reactions. Simulations have been performed at an altitude of $27 \mathrm{~km}$ in the middle stratosphere where the maximum $\mathrm{O}_{3}$ VMR is found. The neutral chemistry model is validated using rate coefficients with a consistency between initialization and the set of reactions provided by the JPL. Reactive species have equilibrium diurnal variations. The plasma chemistry validation reveals differences in the productions of $\mathrm{NO}$ and $\mathrm{O}_{3}$ between MiPO-Streamer model and W2015. The densities of $\mathrm{NO}$ and $\mathrm{O}_{3}$ depend on the densities of excited states of atomic nitrogen and oxygen, which are mostly produced during the BJ streamer discharge 
period. Analysis of $\mathrm{NO}$ and $\mathrm{O}_{3}$ production and loss highlights that the major difference is due to the rate coefficient of $\mathrm{N}_{2}+\mathrm{e}^{-} \rightarrow \mathrm{N}+\mathrm{N}+\mathrm{e}^{-}$, which produces atomic nitrogen.

We have investigated the impact of the streamer representation using two types of electric field time profiles, one is a constant field for a limited duration (pulse), which has been previously used in the literature to estimate the chemical impact of TLEs, and the other one is produced through an electrodynamic discharge model. The results on the densities of neutral species through an electrodynamic streamer simulation show an impact of a factor 2 as compared to the pulse-based simulation at $27 \mathrm{~km}$. Analyzing correlations between electrons and $\mathrm{N}_{2}\left(\mathrm{~A}^{3} \sum_{\mathrm{u}}^{+}\right)$, atomic oxygen, and nitrogen species during discharge process, it is found that the temporal electric field profile considered is critical for an accurate estimate of the streamer impact on chemistry. Higher densities of $\mathrm{N}_{2}\left(\mathrm{~A}^{3} \sum_{\mathrm{u}}^{+}\right)$, atomic oxygen, $\mathrm{O}\left({ }^{1} \mathrm{~S}\right), \Delta \mathrm{O}_{3}$, atomic nitrogen, $\mathrm{N}\left({ }^{2} \mathrm{D}\right), \mathrm{N}\left({ }^{2} \mathrm{P}\right)$, and $\mathrm{NO}_{x}$ are produced using the more realistic streamer field. Moreover, the larger density of $\mathrm{N}_{2}$ excited states is directly linked with light emission density of $\mathrm{BJ}$, and it is an important result that could be confirmed by observations. Our results highlight the importance of using a realistic streamer parameterization to model the time evolution for the electric field.

Looking at neutral chemistry during the first $100 \mathrm{~s}$ of the simulation, $\mathrm{O}_{3}$ and $\mathrm{NO}_{x}$ are produced by BJ. Because of the excess of $\mathrm{NO}_{x}$ VMR produced, the 2-day simulation reveals that $\mathrm{O}_{3} \mathrm{VMR}$ is destroyed through the $\mathrm{NO}_{x}$ catalytic cycle in the middle stratosphere. The produced $\mathrm{O}_{3}$ VMR by streamer discharge is consumed in 1 or 2 days (depending on the considered streamer parameterizations). After 2 days, $\mathrm{O}_{3}$ loss appeared and $\mathrm{O}_{3}$ VMR decreases to lower VMR than that in the no-discharge simulation case.

This study focused on the impact of BJ streamer discharge at $27 \mathrm{~km}$. It is planned to extend the study considering the leader process. For the observation validation, as diffusive mixing is negligible at the altitude of interest in this work, transport processes in the real environment will be considered in the future study. Moreover, we will apply streamer and leader models accounting for the density of streamers and leaders in a $\mathrm{BJ}$, and the frequency of BJ to investigate the regional and global scale impacts.

\section{Acknowledgments}

This study was supported by the French Research Ministry, the Ecole Doctorale (EMSTU) of the Université d'Orléans (PhD Grant), the TARANIS project from CNES (https://taranis.cnes.fr/en/ TARANIS/index.htm), and CNRSINSU. We thank the French AERIS data center. We particularly thank K. Ihaddadene and J-L. Pinçon for helpful scientific discussions. We also thank F. Lefèvre for providing us with the chemical data from REPROBUS CTM model (http://cds-espri.ipsl.fr/) and F. Romand from ONERA for his help on the BOLSIG+ solver, which can be downloaded in the website (www. bolsig.laplace.univ-tlse.fr). The reaction coefficient rates used in this study can be found from the following links: from Winkler (W2015, https://www.atmoschem-phys.net/14/3545/2014/acp-143545-2014-supplement.pdf), and from Jet Propulsion Laboratory (JPL, http://hdl.handle.net/2014/41648). The input and output data from the MiPO-Streamer model of this study could be found in the AERIS data center (https://dataverse.sedoo.fr/ dataset.xhtml?persistentId $=$ doi:10.6096/DV/WE99CG).

\section{References}

André, P. (1997). Numerical method and composition at and out of chemical equilibrium in a multitemperature plasma. Application to a pure nitrogen plasma. Contributions to Plasma Physics, 37(1), 23-40. https://doi.org/10.1002/ctpp.2150370104

Avallone, L. M., \& Prather, M. J. (1996). Photochemical evolution of ozone in the lower tropical stratosphere. Journal of Geophysical Research, 101(D1), 1457-1461. https://doi.org/10.1029/95JD03010

Babaeva, N. Y., \& Naidis, G. (1996). Two-dimensional modeling of positive streamer dynamics in non-uniform electric fields in air. Journal of Physics D: Applied Physics, 29, 2423-2431.

Brogniez, C., Huret, N., Eckermann, S., Rivière, E. D., Pirre, M., Herman, M., et al. (2003). Polar stratospheric cloud microphysical properties measured by the microRADIBAL instrument on 25 January 2000 above Esrange and modeling interpretation. Journal of Geophysical Research, 108(D6). https://doi.org/10.1029/2001JD001017

Celestin, S., \& Pasko, V. P. (2010). Effects of spatial non-uniformity of streamer discharges on spectroscopic diagnostics of peak electric fields in transient luminous events. Geophysical Research Letters, 37(7). https://doi.org/10.1029/2010GL042675

Chameides, W. L., Davis, D. D., Bradshaw, J., Rodgers, M., Sandholm, S., \& Bai, D. B. (1987). An estimate of the $\mathrm{NO}_{x}$ production rate in electrified clouds based on NO observations from the GTE/CITE 1 fall 1983 field operation. Journal of Geophysical Research, 92(D2), 2153-2156. https://doi.org/10.1029/JD092iD02p02153

Chanrion, O., Neubert, T., Mogensen, A., Yair, Y., Stendel, M., Singh, R., \& Singh, D. (2017). Profuse activity of blue electrical discharges at the tops of thunderstorms. Geophysical Research Letters, 44(1), 496-503.

Chou, J. K., Tsai, L. Y., Kuo, C. L., Lee, Y. J., Chen, C. M., Chen, A. B., et al. (2011). Optical emissions and behaviors of the blue starters, blue jets, and gigantic jets observed in the Taiwan transient luminous event ground campaign. Journal of Geophysical Research, 116. https://doi.org/10.1029/2010JA016162

Cohen, R. C., \& Murphy, J. G. (2003). Photochemistry of $\mathrm{NO}_{2}$ in Earth's stratosphere: Constraints from observations. Chemical Reviews, 103(12), 4985-4998. https://doi.org/10.1021/cr020647x

Croizé, L., Payan, S., Bureau, J., Duruisseau, F., Thiéblemont, R., \& Huret, N. (2015). Effect of blue jets on atmospheric composition: Feasibility of measurement from a stratospheric balloon. IEEE Journal of Selected Topics in Applied Earth Observations and Remote Sensing, 8(6), 3183-3192. https://doi.org/10.1109/JSTARS.2014.2381556

Dyakonov, M. I., \& Kachorovsky, V. Yu. (1989). Streamer discharge in a homogeneous field, Zhurnal Eksperimental'noi i Teoreticheskoi Fiziki, vol. 95, pp. 1850-1859, 1989 (Engl. transl.: Sov. Phys. JETP, vol. 68, pp. 1070-1075, 1989).

Gordillo-Vázquez, F. J. (2008). Air plasma kinetics under the influence of sprites. Journal of Physics D: Applied Physics, $41(23), 234016$.

Griffing, G. W. (1977). Ozone and oxides of nitrogen production during thunderstorms. Journal of Geophysical Research, 82(6), 943-950. https://doi.org/10.1029/JC082i006p00943

Grossel, A., Huret, N., Catoire, V., Berthet, G., Renard, J. B., Robert, C., \& Gaubicher, B. (2010). In situ balloon-borne measurements of $\mathrm{HNO}_{3}$ and $\mathrm{HCl}$ stratospheric vertical profiles influenced by polar stratospheric cloud formation during the 2005-2006 Arctic winter. Journal of Geophysical Research, 115. https://doi.org/10.1029/2009JD012947

Hagelaar, G. J. M., \& Pitchford, L. C. (2005). Solving the Boltzmann equation to obtain electron transport coefficients and rate coefficients for fluid models. Plasma Sources Science and Technology, 14(4), 722. 
Huret, N., Pommereau, J. P., Dudok de Witt, T., \& Pirre, M. (2003, April). Modeling study of $\mathrm{NO}_{x}$ species in the lower tropical stratosphere over Brazil on February 2001. In EGS-AGU-EUG Joint Assembly.

Ihaddadene, M. A., \& Celestin, S. (2015). Increase of the electric field in head-on collisions between negative and positive streamers Geophysical Research Letters, 42, 5644-5651. https://doi.org/10.1002/2015GL064623

Ihaddadene, M. A., \& Celestin, S. (2017). Determination of sprite streamers altitude based on $\mathrm{N}_{2}$ spectroscopic analysis. Journal of Geophysical Research: Space Physics, 122, 1000-1014. https://doi.org/10.1002/2016JA023111

Johnston, H. (1971). Reduction of stratospheric ozone by nitrogen oxide catalysts from supersonic transport exhaust. Science, 173(3996), 517-522. https://doi.org/10.1126/science.173.3996.517

Kossyi, I. A., Kostinsky, A. Y., Matveyev, A. A., \& Silakov, V. P. (1992). Kinetic scheme of the non-equilibrium discharge in nitrogen-oxygen mixtures. Plasma Sources Science and Technology, 1(3), 207.

Krehbiel, P. R., Riousset, J. A., Pasko, V. P., Thomas, R. J., Rison, W., Stanley, M. A., \& Edens, H. E. (2008). Upward electrical discharges from thunderstorms. Nature Geoscience, 1(4), 233. https://doi.org/10.1038/ngeo162

Lefèvre, F., Brasseur, G. P., Folkins, I., Smith, A. K., \& Simon, P. (1994). Chemistry of the 1991-1992 stratospheric winter: Three-dimensional model simulations. Journal of Geophysical Research, 99(D4), 8183-8195. https://doi.org/10.1029/93JD03476

Lefèvre, F., Figarol, F., Carslaw, K. S., \& Peter, T. (1998). The 1997 Arctic ozone depletion quantified from three-dimensional model simulations. Geophysical Research Letters, 25(2425-2428), 1998. https://doi.org/10.1029/98GL51812

MacGorman, D. R., \& Rust, W. D. (1998). The electrical nature of storms. Oxford University Press on Demand.

Mishin, E. V. (1997). Ozone layer perturbation by a single blue jet. Geophysical Research Letters, 24(15), 1919-1922. https://doi.org/10.1029/ 97GL01890

Mishin, E. V., \& Milikh, G. M. (2008). Blue jets: Upward lightning. Space Science Reviews, 137(1-4), 473-488. https://doi.org/10.1007/ s11214-008-9346-Z

Mitchell, J. D., \& Hale, L. C. (1973). Observations of the lowest ionosphere. Space Res, 13, 471-476.

Murphy, D. M., Fahey, D. W., Proffitt, M. H., Liu, S. C., Chan, K. R., Eubank, C. S., et al. (1993). Reactive nitrogen and its correlation with ozone in the lower stratosphere and upper troposphere. Journal of Geophysical Research, 98(D5), 8751-8773. https://doi.org/10.1029/ 92JD00681

Naidis, G. V. (2009). Positive and negative streamers in air: Velocity-diameter relation. Physical Review E, 79, 057401. https://doi.org/ 10.1103/PhysRevE.79.057401

Neubert, T., Rycroft, M., Farges, T., Blanc, E., Chanrion, O., Arnone, E., et al., et al. (2008). Recent results from studies of electric discharges in the mesosphere. Surveys in Geophysics, 29(2), 71-137. https://doi.org/10.1007/s10712-008-9043-1

Pasko, V. P., Inan, U. S., \& Bell, T. F. (1996). Sprites as luminous columns of ionization produced by quasi-electrostatic thundercloud fields. Geophysical Research Letters, 23(6), 649-652. https://doi.org/10.1029/96GL00473

Pasko, V. P., Inan, U. S., \& Bell, T. F. (1998). Spatial structure of sprites. Geophysical Research Letters, 25, 2123-2126. https://doi.org/ 10.1029/98GL01242

Pasko, V. P., Stanley, M. A., Mathews, J. D., Inan, U. S., \& Wood, T. G. (2002). Electrical discharge from a thundercloud top to the lower ionosphere. Nature, 416(6877), 152-154. https://doi.org/10.1038/416152a

Peterson, H., Bailey, M., Hallett, J., \& Beasley, W. (2009). $\mathrm{NO}_{x}$ production in laboratory discharges simulating blue jets and red sprites. Journal of Geophysical Research, 114. https://doi.org/10.1029/2009JA014489

Petrov, N. I., \& Petrova, G. N. (1999). Physical mechanisms for the development of lightning discharges between a thundercloud and the ionosphere. Technical Physics, 44(4), 472-475. https://doi.org/10.1134/1.1259327

Popov, N. A. (2002). Spatial structure of the branching streamer channels in a corona discharge. Plasma Physics Reports, 28(7), 615-622. https://doi.org/10.1134/1.1494061

Popov, N. A., Shneider, M. N., \& Milikh, G. M. (2016). Similarity analysis of the streamer zone of blue jets. Journal of Atmospheric and Solar-Terrestrial Physics, 147, 121-125. https://doi.org/10.1016/j.jastp.2016.07.003

Portmann, R. W., Daniel, J. S., \& Ravishankara, A. R. (2012). Stratospheric ozone depletion due to nitrous oxide: Influences of other gases. Philosophical Transactions of the Royal Society, B: Biological Sciences, 367(1593), 1256-1264. https://doi.org/10.1098/ rstb.2011.0377

Prather, M. J., \& Watson, R. T. (1990). Stratospheric ozone depletion and future levels of atmospheric chlorine and bromine. Nature, 344(6268), 729. https://doi.org/10.1038/344729a0

Raizer, Y. P., Milikh, G. M., \& Shneider, M. N. (2006). On the mechanism of blue jet formation and propagation. Geophysical Research Letters, 33(23). https://doi.org/10.1029/2006GL027697

Raizer, Y. P., Milikh, G. M., \& Shneider, M. N. (2007). Leader-streamers nature of blue jets. Journal of Atmospheric and Solar-Terrestrial Physics, 69(8), 925-938. https://doi.org/10.1016/j.jastp.2007.02.007

Ramaroson, R., Pirre, M., \& Cariolle, D. (1992, June). A box model for on-line computations of diurnal variations in a 1-D model-Potential for application in multidimensional cases. In Annales geophysicae, 10, 416-428.

Rivière, E. D., Huret, N., Taupin, F. G., Renard, J. B., Pirre, M., Eckermann, S. D., et al. (2000). Role of lee waves in the formation of solid polar stratospheric clouds: Case studies from February 1997. Journal of Geophysical Research, 105(D5), 6845-6853. https://doi.org/ 10.1029/1999JD900908

Riviere, E. D., Pirre, M., Berthet, G., Renard, J. B., Taupin, F. G., Huret, N., et al. (2002). On the interaction between nitrogen and halogen species in the Arctic polar vortex during THESEO and THESEO 2000. Journal of Geophysical Research, 107(D5). https://doi.org/10.1029/ 2002JD002087

Sander, S. P., Golden, D. M., Kurylo, M. J., Moortgat, G. K., Wine, P. H., Ravishankara, A. R., et al. (2006. Chemical kinetics and photochemical data for use in atmospheric studies evaluation number 15. Pasadena, CA: Jet Propulsion Laboratory, National Aeronautics and Space Administration. http://hdl.handle.net/2014/41648

Sentman, D. D., Stenbaek-Nielsen, H. C., McHarg, M. G., \& Morrill, J. S. (2008). Plasma chemistry of sprite streamers. Journal of Geophysical Research, 113(D11). https://doi.org/10.1029/2007JD008941

Smirnova, N. V., Lyakhov, A. N., \& Kozlov, S. I. (2003). Lower stratosphere response to electric field pulse. International Journal of Geomagnetism and Aeronomy, 3(3), 281-287.

Sukhorukov, A. I., \& Stubbe, P. (1997). Excitation of the ionospheric Alfven resonator by strong lightning discharges. Geophysical Research Letters, 24(8), 829-832.

Wescott, E. M., Sentman, D. D., Heavner, M. J., Hampton, D. L., Osborne, D. L., \& Vaughan, O. H. Jr. (1996). Blue starters Brief upward discharges from an intense Arkansas thunderstorm. Geophysical Research Letters, 23(16), 2153-2156. https://doi.org/10.1029/ 96GL01969 
Wiesmann, H. J., \& Pietronero, L. (1986). Properties of Laplacian fractals for dielectric breakdown in 2 and 3 dimensions. In Fractals in Physics, 151-157. https://doi.org/10.1016/B978-0-444-86995-1.50030-5

Winkler, H., \& Notholt, J. (2014). The chemistry of daytime sprite streamers-A model study. Atmospheric Chemistry and Physics, 14(7), 3545-3556. https://doi.org/10.5194/acp-14-3545-2014

Winkler, H., \& Notholt, J. (2015). A model study of the plasma chemistry of stratospheric Blue Jets. Journal of Atmospheric and Solar-Terrestrial Physics, 122, 75-85. https://doi.org/10.1016/j.jastp.2014.10.015

Yung, Y. L., Pinto, J. P., Watson, R. T., \& Sander, S. P. (1980). Atmospheric bromine and ozone perturbations in the lower stratosphere. Journal of the Atmospheric Sciences, 37(2), 339-353. https://doi.org/10.1175/1520-0469(1980)037 < 0339:ABAOPI>2.0.CO; 